\title{
An epidemic of acute postinfectious glomerulonephritis in Armenia
}

Ashot Sarkissian, Marina Papazian, Gayane Azatian, Nina Arikiants, Ara Babloyan, Ernst Leumann

\begin{abstract}
Aim-To evaluate the presentation and course of acute postinfectious glomerulonephritis (APGN), which has increased dramatically in Armenia after serious deterioration in the living conditions.

Study design-Observational study, based on case notes, of a large homogeneous group of patients hospitalised for APGN at one centre over a five year period (1992-6). Patients -474 patients aged $<16$ years with a diagnosis of APGN.

Results-The annual number of patients increased tenfold from 19 (average 1992/3) to 196 in 1995 . Sixty two per cent were in the age group 4-9 years and $65 \%$ were boys. Upper respiratory infections, scarlet fever, and skin infections preceded APGN in $51 \%, 23 \%$, and $13 \%$, respectively. All patients had haematuria (93\% gross), $84 \%$ had oedema, and $72 \%$ had hypertension. C3 was initially decreased in $95 \%$ of the patients examined. Renal function was impaired (serum creatinine $>100 \mu \mathrm{mol} / \mathrm{l}$ ) in $29 \%$. Four patients with renal failure had crescentic glomerulonephritis at biopsy; of these, three required temporary haemodialysis. Main extrarenal complications were heart failure $(\mathbf{1 0 \%})$ and convulsions $(3 \%)$. One patient died and five $(3 \%)$ did not recover completely.

Conclusions-APGN in children is associated with considerable initial morbidity, and long term outcome is not uniformly benign. Outbreaks of APGN may occur anytime in countries such as Armenia that are suffering from a sudden decline in socioeconomic conditions.

(Arch Dis Child 1997;77:342-344)
\end{abstract}

Children's Medical Centre 'Arabkir', Yerevan, Armenia

A Sarkissian

M Papazian

G Azatian

$\mathrm{N}$ Arikiants

A Babloyan

University Children's Hospital,

Steinwiesstrasse 75, CH 8032 Zurich, Switzerland

E Leumann

Correspondence to: Professor Leumann.

Accepted 2 July 1997 treak of APGN in Armenia after a seri deterioration in the living conditions has prompted us to study the clinical features and outcome of the disease.

\section{Patients and methods}

This observational study based on a review of the case notes includes 474 children with APGN from the Arabkir Hospital in Yerevan. The diagnosis was based on the history, the typical clinical features, urinalysis, renal function, and C3. Hypertension was defined as systolic and/or diastolic blood pressure values exceeding the 95th centile for age and sex. ${ }^{10}$ Haematuria was diagnosed when the number of red blood cells was greater than $5 /$ high power field in centrifuged urine. $\mathrm{C} 3$ concentration in serum was measured by radial immunodiffusion (NOR-Partigen- $\mathrm{C}_{3}$, provided by Behring Diagnostika AG, Zurich, Switzerland) in 157 patients. No throat cultures were done. All patients received penicillin or analogues for 14 days. Frusemide and nifedipine were given when indicated. Full recovery was defined as the absence of oedema and hypertension, normal renal function, and repeatedly normal urinalyses.

\section{Results}

Between 1992 and 1996474 patients with APGN were admitted to the nephrology department; a large increase was noted in 1994 and 1995 (fig 1). The age ranged between 1 and 16 years (average 7.5 years); the majority $(62 \%)$ was in the age group 4-9 years (fig 2). Only one patient was less than 2 years old, and two thirds $(65 \%)$ were boys.

An upper respiratory tract infection preceded APGN in 242 patients (51\%), scarlet fever in 107 (23\%), and impetigo in 64 (13\%). Impetigo was superimposed on scabies in 22 children. The proportion of patients with scarlet fever increased from 5\% in 1992 to $35 \%$ in 1995 (fig 1). Enlarged cervical lymph nodes of unknown origin were noticed in $23(5 \%)$ patients. No focus was found in 38 children $(8 \%)$. There were 11 familial cases in five families.

Table 1 shows the main clinical findings. The majority of patients had gross haematuria, oedema, and hypertension. Renal function was impaired (serum creatinine $>100 \mu \mathrm{mol} / \mathrm{l}$ ) in $134(29 \%)$. Five patients developed the nephrotic syndrome with haematuria. Of these, four had presented with acute renal failure (serum creatinine 700-1200 $\mu \mathrm{mol} / \mathrm{l}$ ); three required temporary haemodialysis. Congestive heart failure with pulmonary oedema was diagnosed 
Table 1 Initial clinical findings $(n=474)$

\begin{tabular}{lc}
\hline Symptoms & No of patients (\%) \\
\hline Haematuria & $442(93)$ \\
$\quad$ Gross & $32(7)$ \\
Microscopic & $397(84)$ \\
Oedema & $340(72)$ \\
Hypertension & $5(1)$ \\
Nephrotic syndrome & \\
Impaired renal function: & \\
Serum creatinine & $126(27)$ \\
$\quad 100-299 \mu$ mol/1 & $8(2)$ \\
$\quad \geqslant 300 \mu$ mol/1 & $45(10)$ \\
Circulatory congestion & $16(3)$ \\
Seizures & \\
\hline
\end{tabular}

in $45(10 \%)$ patients; three needed artificial ventilation and one died. Sixteen patients (3\%), all with blood pressure values exceding $150 / 100 \mathrm{~mm} \mathrm{Hg}$, had seizures.

Hypocomplementaemia found in $95 \%$ of the 157 patients examined in the first week of disease normalised in half of them during the first three weeks. After three months, only one child had a low serum C3 concentration despite normal urine and renal function.

Percutaneous renal biopsies were performed in seven children. One patient with prolonged gross haematuria and two with extrarenal symptoms had endocapillary proliferation. A renal biopsy specimen taken from the four patients with acute renal failure showed extensive extracapillary proliferation (crescentic

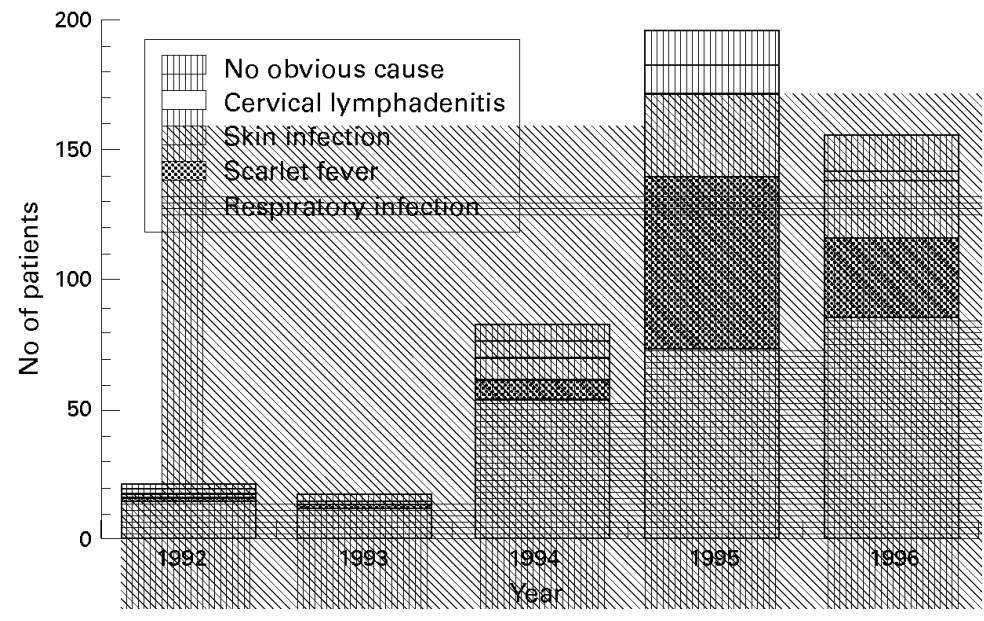

Figure 1 Number of patients per year and infections preceding APGN.

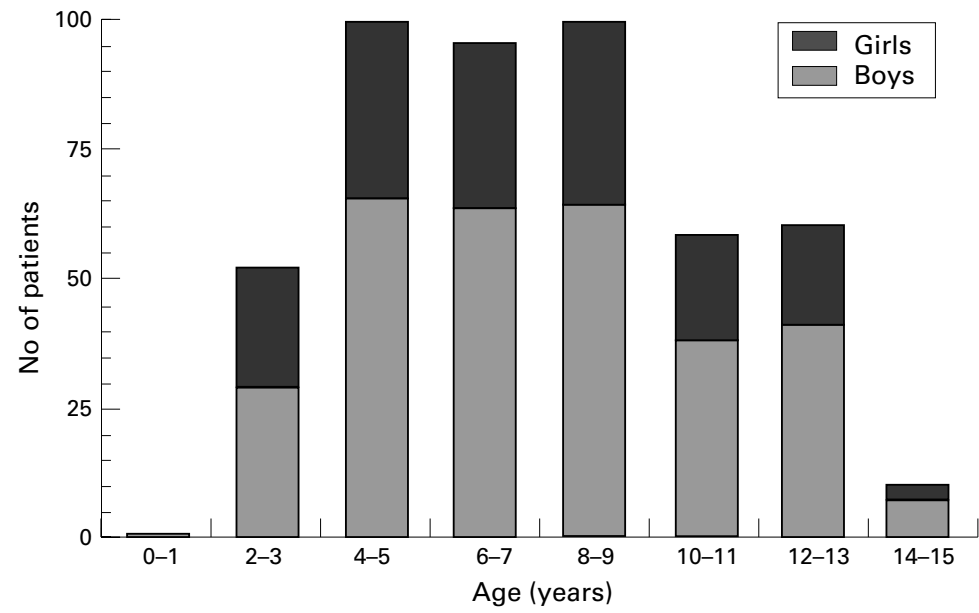

Figure 2 Age distribution and gender. glomerulonephritis) with numerous 'humps' on electron microscopy in one. Hypocomplementaemia and an increased antistreptolysin $\mathrm{O}$ titre were noted in three of them. All four had a preceding infection (two impetigo and two respiratory infection). They had additional treatment by prednisone and cyclophosphamide. Renal function improved partially in three, whereas the remaining patient developed end stage renal failure within seven months.

Complete remission was noted at follow up in $78 \%$ of 362 children after three months and in $97 \%$ of 171 children examined after one year.

\section{Discussion}

The number of children (474) with APGN described in this report, all admitted to one single institution during a period of only five years, is one of the largest published series. ${ }^{24}$ The incidence and cause of APGN is strongly influenced by social, economic, and environmental conditions. ${ }^{1-7} 11$ Outbreaks of the disease coincide with economic decline, poor hygiene, and insufficient medical care. ${ }^{512-14}$ Resurgence of APGN, although to a lesser extent, has also been noted in Japan, Western Europe, and North America. ${ }^{19}{ }^{15}$ The number of patients in this epidemic in Armenia is even more impressive when taking into account the small population (three million) of the country. The estimated incidence in 1995 for the age group prone to develop APGN (4-9 years) was 50 cases per 100000 . This figure is even higher than that observed in Santiago de Chile in 1986 (32 per 100000 ), one of the highest so far reported, ${ }^{16}$ apart from the epidemics in Trinidad and Maracaibo. ${ }^{24}$ The age distribution in Armenia affecting predominantly preschool and school aged children and the male preponderance were comparable with other series. ${ }^{413}$ Although we could not study the pathogenic strains, there is little doubt that nephritogenic $\beta$-haemolytic streptococci of group A were the responsible micro-organism in most, if not all, cases, considering the transient hypocomplementaemia and parallel increase of the number of children with scarlet fever and skin infections.

The combination of gross haematuria, oedema, and hypertension, that is, the nephritic syndrome - the classic manifestation of APGN-was seen in the large majority of our patients. Only $16 \%$ had isolated urinary abnormalities. However, it is likely that many mild or subclinical cases of APGN remained undetected. The nephrotic syndrome is a rare manifestation of APGN. ${ }^{17}$ Only five patients in our series were nephrotic, and a renal biopsy specimen taken from the four with renal failure showed crescentic glomerulonephritis. This lesion, which usually corresponds to rapidly progressive glomerulonephritis, has several aetiologies ${ }^{18}$; of these, APGN is a rare one, at least in children. ${ }^{12131920}$ Out of 30 patients with crescentic glomerulonephritis in London, only two had APGN. ${ }^{19}$

Transient impairment of renal function is common, and APGN is still an important cause of acute renal failure in some countries. ${ }^{12}$ 


\section{Key messages}

- Outbreaks of APGN may occur anywhere after a decline in socioeconomic conditions

- $\mathrm{APGN}$ is the prevailing glomerular disease in children worldwide

- APGN is associated with considerable initial morbidity

- The long term prognosis of APGN in children is not uniformly benign

Thanks to modern treatment, the mortality rate in the acute phase is now low $(<1 \%) .{ }^{21}$ One of our patient died of congestive heart failure.

The long term outcome of childhood APGN is generally very good-in contrast with the situation in adults ${ }^{22}$ - with hypertension or mild urinary abnormalities persisting in only a low proportion of patients, ${ }^{11212324}$ although in one study $20 \%$ had mild residua. ${ }^{25}$ Complete remission was noticed in $97 \%$ of our patients after one year.

What was causing this epidemic of APGN in a country not considered to be a developing country in the traditional sense? Armenia suffered an abrupt economic decline, starting in 1990, which led to precarious living conditions with no heating and lack of medical care and drugs. The poor hygienic situation is illustrated by the increasing number of skin infections, which often were superimposed on scabies. This present epidemic occurred with a delay of two to three years and appears now to be slowly disappearing with the gradual improvement in general living conditions in Armenia. This report clearly shows that APGN remains an important paediatric disease and that outbreaks may occur in countries where this disease had been under control for a long time.

1 Masuyama T, Ishii E, Muraoka $\mathrm{K}$, et al. Outbreak of acute glomerulonephritis in children: observed association with glomerulonephritis in children: observed association with Kyushu, Japan. Acta Paediatr fpn 1996;38:128-31.

2 Poon-King T, Mohammed I, Cox R, et al. Recurrent epidemic nephritis in South Trinidad. N Engl f Med 1967; 277:728-33.
3 Reinstein CR. Epidemic nephritis at Red Lake, Minnesota. 7 Pediatr 1955;47:25-34

4 Rodriguez-Iturbe B, Garsia R, Rubio L, et al. Epidemic glomerulonephritis in Maracaibo. Evidence for progression to chronicity. Clin Nephrol 1976;5:197-206.

5 Streeton CL, Hanna JN, Messer RD, Merianos A. An epidemic af acute post-streptococcal glomerulonephritis among aboriginal children. 7 Paediatr Child Health 1995;31:245-8.

6 Zimmerman R, Gross M, Miller DR, et al. A streptococcal epidemic in an isolated civilian population with institution of mass prophylaxis. F Pediatr 1966;69:40-5.

7 Yap H-K, Chia K-S, Murugasu B, et al. Acute glomerulonephritis - changing patterns in Singapore children. Pediatr Nephrol 1990;4:482-4

8 Roy S, Stapleton FB. Changing perspectives in children hospitalized with poststreptococcal acute glomerulonephritis. Pediatr Nephrol 1990;4:585-8.

9 Simon P, Ramee M-P, Autuly V, et al. Epidemiology of primary glomerular disease in a French region. Variations according to period and age. Kidney Int 1994;46:1192-8.

10 Report of the second task force on blood pressure control in children, 1987. Pediatrics 1987;79:1-25.

11 Dodge WF, Spargo BH, Travis LR, et al. Poststreptococcal glomerulonephritis. A prospective study in children. $\mathrm{N} \mathrm{Engl}$ glomed 1972;286:273-8.

12 Arora P, Kher V, Rai PK, et al. Prognosis of acute renal failure in children: a multivariate analysis. Pediatr Nephrol 1997;11:153-5.

13 Oner A, Demircin G, Bulbul M. Post-streptococcal acute glomerulonephritis in Turkey. Acta Paediatr 1995;84:8179.

14 Shiva F, Far RR, Behjati MR. Acute glomerulonephritis in children. Fournal of the Pakistani Medical Association 1994;44:116-8.

15 Gunzenhauser JD, Longfield JN, Brundage JF, et al. Epidemic streptococcal disease among army trainees, July 1989 through June 1991. F Infect Dis 1995;172:124-31.

16 Berrios X, Quesney G, Morales A, et al. Acute rheumatic fever and poststreptococcal glomerulonephritis in an open
population: comparative studies of epidemiology and population: comparative studies of epid
bacteriology. F Lab Clin Med 1986;6:146-8.

17 Prakash JJ, Tripathi K, Usha, et al. Nephrotic syndrome in poststreptococcal glomerulonephritis. F Indian Med Assoc 1986;84:105-6.

18 Couser WG. Rapidly progressive glomerulonephritis: classification, pathogenetic mechanisms, and therapy. $A m \mathcal{F}$ Kidney Dis 1988;11:449-64.

19 Jardim HM, Leake J, Risdon RA, et al. Crescentic glomerulonephritis in children. Pediatr Nephrol 1992;6:231-5.

20 Modai D, Pik A, Behar M, et al. Biopsy proven evolution of post streptococcal glomerulonephrits to rapidly progressive post streptococcal glomerulonephrits to rapidly progressive
glomerulonephritis of a post infectious type. Clin Nephrol 1985;23:198-202.

21 Popovic-Rolovic M, Kostic M, Antic-Peco A, et al. Medium and long-term prognosis of patients with acute poststreptococcal glomerulonephritis. Nephron 1991;58:393-9.

22 Baldwin DS, Gluck MC, Schacht RG, Gallo G. The long-term course of poststreptococcal glomerulonephritis. Ann Intern Med 1974;80:342-58.

23 Travis LR, Dodge WF, Beathard GA, et al. Acute glomerulonephritis. a review of the natural history with emphasis on prognosis. Clin Nephrol 1973;1:169-81.

24 Potter EV, Lipschulte SA, Abidh S, et al. Twelve to seventeen-year follow-up of patients with poststreptococcal glomerulonephritis in Trinidad. $N$ Engl $\mathfrak{F}$ Med 1982;307: glomer

25 Clark G, White RHR, Glasgow EF, et al. Poststreptococcal glomerulonephritis in children: clinicopathological correlation and long-term prognosis. Pediatr Nephrol 1988;2:3818. 